\title{
Volumetric conversion of allocations: a means to an end or an important process in its own right?
}

\author{
M. A. Skewes ${ }^{1} \&$ R. Carruthers ${ }^{2}$ \\ ${ }^{I}$ South Australian Research and Development Institute, Australia \\ ${ }^{2}$ Queensland Department of Natural Resources and Mines, Australia
}

\begin{abstract}
Volumetric allocation of irrigation water is government policy in South Australia. All newly prescribed water resources are allocated volumetrically. Irrigation licences existing prior to implementation of the policy are being converted to volumetric allocations.

The desired outcomes of a successful allocation conversion process are a good matching between resource availability and allocated licence volumes, and minimal legal challenges to the new system. Achieving these dual outcomes can be extremely challenging, but is critical to the sustainability of irrigation in the region.

The Limestone Coast volumetric conversion process encapsulated around 2,500 water licences, covering about 6,000 groundwater bores and an allocated equivalent volume of over 630,000 megalitres from two regional aquifers. The conversion process employed a range of activities, and took over 4 years to develop.

The community response to the conversion process strongly suggests that the considerable effort and resources expended to do this job thoroughly and equitably was well worthwhile, and further, augers well for the ongoing sustainability of irrigation in this region.
\end{abstract}

Keywords: volumetric conversion, water allocation, irrigation licences, community consultation, groundwater. 


\section{Introduction}

\subsection{Background}

In the year 2000, the South Australian Government released its State Water Plan (Department for Environment, Heritage and Aboriginal Affairs [1]). One of the key objectives set out in the plan was that all water allocations in South Australia would be converted to a volumetric basis, and all water use measured. In response to this action, the Limestone Coast region saw the commencement of the single largest water license conversion program in the state.

\subsection{The Limestone Coast}

Previously known simply as the South East, the Limestone Coast region is located in the south east corner of South Australia (Figure 1). It covers some 28,000 square kilometres (South East Catchment Water Management Board [2]), and includes some of the most productive agricultural land in the state. The landscape is composed of a series of stranded coastal dune ranges aligned parallel to the current coast, and separated by flats. The southern portion of the region is characterised by limestone geology.

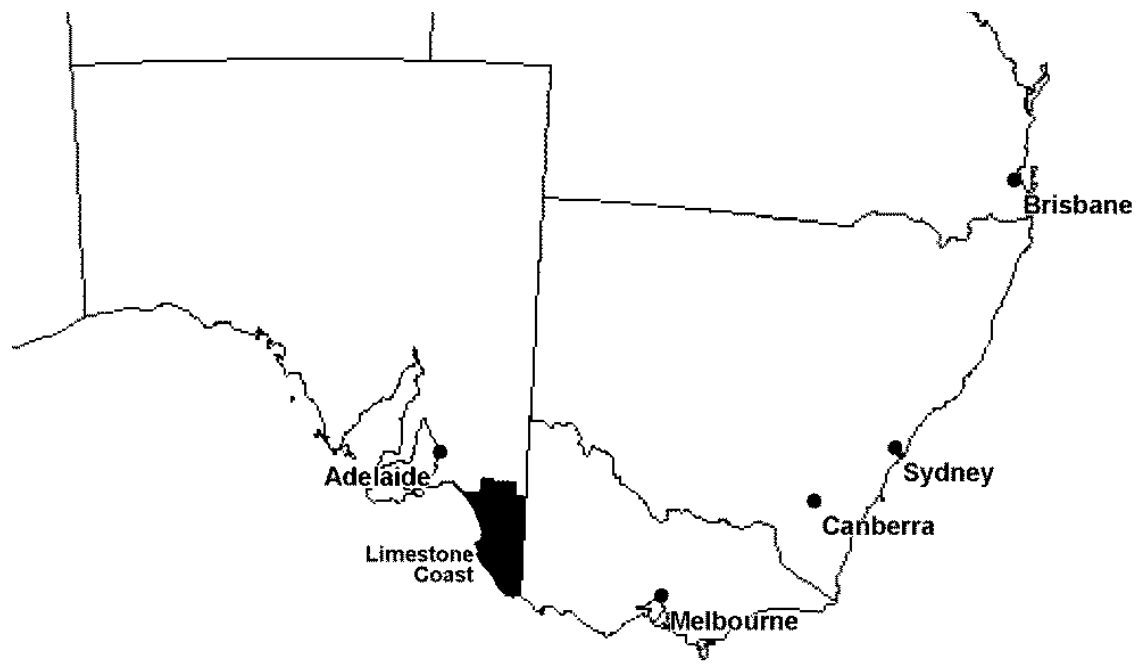

Figure 1: Location of the Limestone Coast.

The Limestone Coast is endowed with a number of aquifer systems. The water quality of these aquifers is somewhat variable, but is generally suitable for irrigation purposes. Shallow unconfined aquifers are recharged from local rainfall. In many places these aquifers are very close to the soil surface, and therefore pumping costs are low. A large confined aquifer underlies the region, recharged many hundreds of kilometres to the north east, so that the water drawn 
from this aquifer is many hundreds of years old. This aquifer is artesian in some areas of the Limestone Coast.

The aquifers have been used for many years to irrigate large areas of pasture, lucerne (alfalfa) for hay and seed, vegetables and vegetable seeds, orchards and vineyards.

At the time of conversion the Limestone Coast was divided into five Prescribed Wells Areas, each with their own area based allocation system. There were approximately 2,500 existing irrigation licences, covering some 6,000 unmetered bores, providing an on-paper allocated volume in excess of 630,000 megalitres.

\subsection{Existing area based licensing system}

The area based licensing system which was in place before conversion was based on Hectare Irrigation Equivalents (HaIE). These HaIEs represented the nominal volume of water required to irrigate a hectare of the reference crop, generally taken as equivalent to pasture.

The actual area of a crop which could be irrigated under this system was calculated according to the crop type(s) to be grown, by the use of Crop Area Ratios (CAR). For example, if the CAR for crop type A was 2.5, then for each HaIE on a licence, $2.5 \mathrm{Ha}$ of crop A could be irrigated.

Management of water resources under this system required the completion of an Annual Water Use Return by every licence holder, detailing the crop types and areas irrigated in the preceding season. Government staff were required to review all of these documents to establish that the areas irrigated complied with the HaIEs on each licence. Satellite photographs were used in some instances to cross check that the reported areas were accurate.

The key drawback of this system was that the volume of water pumped from the aquifer was not managed in any way, only the area of lands on to which this water could be applied. Not only was the volume pumped not managed, it was also not measured, and was therefore unknown, making management of the water resource rather more difficult. The conversion of licences to volumes, and the associated metering of volumes pumped, is critical to improved management of water resources into the future.

\subsection{Volumetric conversion project}

Conversion of so many licences and such a large volume of water to a new volumetric basis was a massive challenge. A full time team of 3 staff were appointed within the then Department of Water Land and Biodiversity Conservation, with part time technical support provided by Primary Industries and Resources SA. A management committee was also established consisting of representatives of a number of government departments and statutory bodies. The project was funded for 4 years, at a cost of $\$ 2.275$ million.

The ultimate success of this project was due in large part to the process undertaken by the project team, which successfully married a scientific approach to determining water allocations with a participative community consultation 
process. The end result was the development of a model which satisfied the needs and aspirations of the government, resource managers, irrigators and the wider community.

\section{Conversion project methodology}

The methodology pursued in the Volumetric Conversion Project made use of internationally recognised scientific methods, validated through local data collection, all in the context of intensive community consultation.

\subsection{Internationally recognised methodology}

Volumetric allocations for the Limestone Coast were determined using internationally recognised science. Gridded evapotranspiration and rainfall data provided by the Bureau of Meteorology was used to draw contours of irrigation requirement across the Limestone Coast. These contours were used as the basis for creating Climate Bands (Figure 2), using existing cadastral boundaries (administrative unit boundaries).

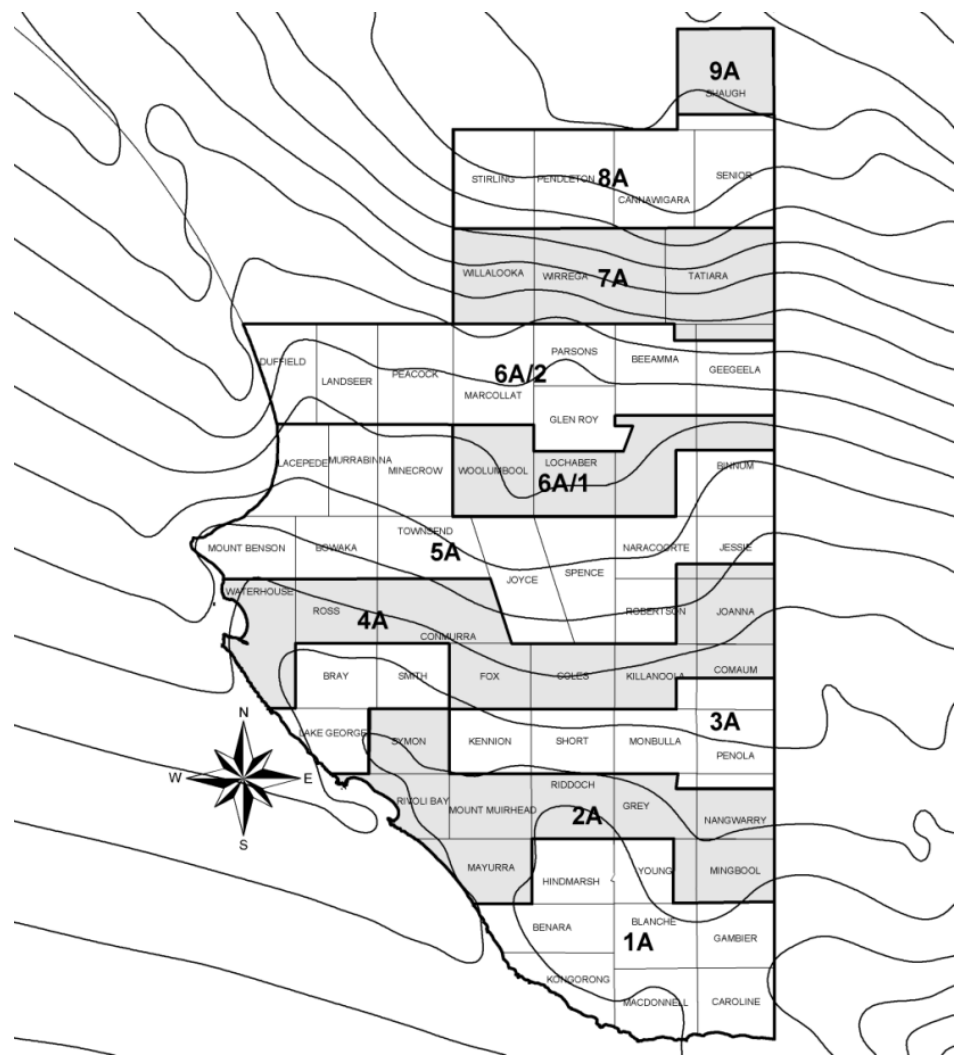

Figure 2: $\quad$ Irrigation requirement contours and resultant climate bands. 
Crop evapotranspiration $\left(\mathrm{ET}_{\mathrm{C}}\right)$ was determined for each climate band by the methodology of Allen et al. [3], using long term average Reference Crop Evapotranspiration $\left(\mathrm{ET}_{0}\right)$, and crop coefficients $\left(\mathrm{K}_{\mathrm{C}}\right)$ from Allen et al. [3] where available. Full discussion of this component of the project is presented in Skewes [4].

Variation in application efficiency between irrigation system types (for example see Phocaides [5], Table 11) was also accommodated in the calculation of final allocations, as set out in Latcham et al. [6].

\subsection{Local data collection}

A key focus of the volumetric conversion project was the collaborative collection of real data from across the Limestone Coast. This was important not just to ensure that the conversion process was appropriate, but to provide credibility to the process, a vital thing if the community were to accept the final conversion.

This local data was incorporated into calculations of crop evapotranspiration (Skewes [4]), delivery component and bridging volume (Latcham et al. [6]), and specialised production requirements (Pudney et al. [7]). Four primary data collection methods were put in place, in order to collect data at different levels of detail and accuracy.

\subsubsection{Community workshops}

These workshops fulfilled a number of important functions, and will be discussed further below. However, in the context of local data collection, the workshops were used as the venue for collection of information about crop calendars for the calculation of $\mathrm{ET}_{\mathrm{C}}$. Irrigators worked together to outline the local crop calendars for the crops which they grew, and the calendars from each workshop were compared. For most crops a single crop calendar was determined for the whole Limestone Coast region, but in a couple of cases there were 2 crop calendars, one each for the northern and southern portions of the region.

\subsubsection{Field Irrigation System Trials}

The Field Irrigation System Trials (FIST) were instrumented sites established on irrigated properties to collect detailed data about on-farm water balance. There were 36 FIST sites established, each incorporating continuous monitoring of soil moisture, water table level, weather data and water meter readings.

The FIST sites provided the highest level of detail in on-farm data, and were targeted to cover a range of geographic locations, crop types and irrigation systems.

\subsubsection{Metered Extraction Trials}

The Metered Extraction Trials (MET) relied on irrigators collecting detailed records of irrigation events and water meter readings, to provide a picture of their irrigation management. These sites were also targeted to cover a range of geographic locations, crops and system types; with 160 MET sites the coverage was more complete than the FIST sites, albeit at a lower level of detail. 
At the time when the MET program was instigated, water meters were not compulsory. However, in order to encourage irrigators to install meters subsidies were offered through the Volumetric Conversion Project, in return for access to the data generated from those meters.

\subsubsection{Annual water use returns}

Finally, as a requirement under the previous area based licensing system, every irrigator in the Prescribed Wells Areas in the Limestone Coast region was required to fill in an Annual Water Use Return. This report initially only provided data on crop types and areas irrigated.

However, for the purpose of the Volumetric Conversion Project, irrigators were asked to also provide data on estimated volumes extracted per season, based on such things as pump hours, and water meter readings if they owned water meters. This data covered almost every irrigation license in the Limestone Coast, and therefore provided full geographical, crop and system type cover, but at the lowest level of detail and accuracy.

\subsection{Community consultation}

True consultation with the community affected by the conversion of water licenses was seen as the key to the success of this conversion process. The history of water management in the region contains examples of poor consultation and bureaucratic overriding of communities' wishes. Thus there was a high level of suspicion of the volumetric conversion process at the beginning of this project. As a result, true consultation with the community was a key objective of the project, and this was put into practice in a number of ways. Detailed discussion of the community consultation process is presented by Carruthers [8].

\subsubsection{Collection of local data}

As already discussed, local data collection was important from a technical perspective, but it was also critical from a consultation perspective. The collection of data from local properties, and the explicit use of this data to validate and adjust the internationally recognised methodology, reinforced that the process was not about importing a method and forcing it onto the local situation, but rather that the method to be used would be developed to fit the local situation. It also gave the community a stake in the methodology, as it was based on their own data, and they had a hand in shaping the final outcome.

\subsubsection{Project advisory committee}

A Project Advisory Committee made up of local industry representatives was instigated early in the project. This committee reviewed all of the activities of the project, and discussed the process and the outcomes as the project progressed.

The committee represented as many of the industries in the region as possible, and the review of progress and proposals at this forum was a good defence against development of bias toward any particular industry(s). 


\subsubsection{Community consultation workshops}

Perhaps the most important consultation process undertaken was the community consultation workshops. These workshops were open to anyone who wished to participate, and were held in as many locations across the region as possible.

In the first round of workshops this translated into a total of 18 workshops over the course of 2 weeks. Five (5) rounds of workshops were undertaken, for a total of 83 workshops, with 1400 participants.

The workshops were the venue for a range of consultation processes. They were the primary means of communicating the methodology being used, progress to date, and current thoughts on the final outcomes of the process.

The workshops were also a data collection opportunity. During the initial round of workshops data was collected about crop calendars, as discussed above. The outcomes of this, in the form of generalised calendars, were presented at the following workshop series, with the opportunity for revision.

Each round of workshops incorporated information about activities undertaken since the last series, including how concerns raised during the previous series had been dealt with. This demonstrated that concerns expressed at the workshops were addressed, and reinforced that consultation was real, not just for the sake of appearances. This in turn built trust in the process.

Another feature of the workshops was a "Myth-busting" session. This picked up on the many rumours circulating about volumetric conversion, and allowed the truth about each issue to be expressed; even when the answer was "we don't know yet". The myth-busting session was presented in a light-hearted manner, and provided comic relief while dealing with serious issues.

The interactive nature of the workshops, and the fact that the workshops were repeated over 5 rounds, was intentional, in order to meet the model of input and feedback, as presented in Figure 3 (from Carruthers et al. [9]).

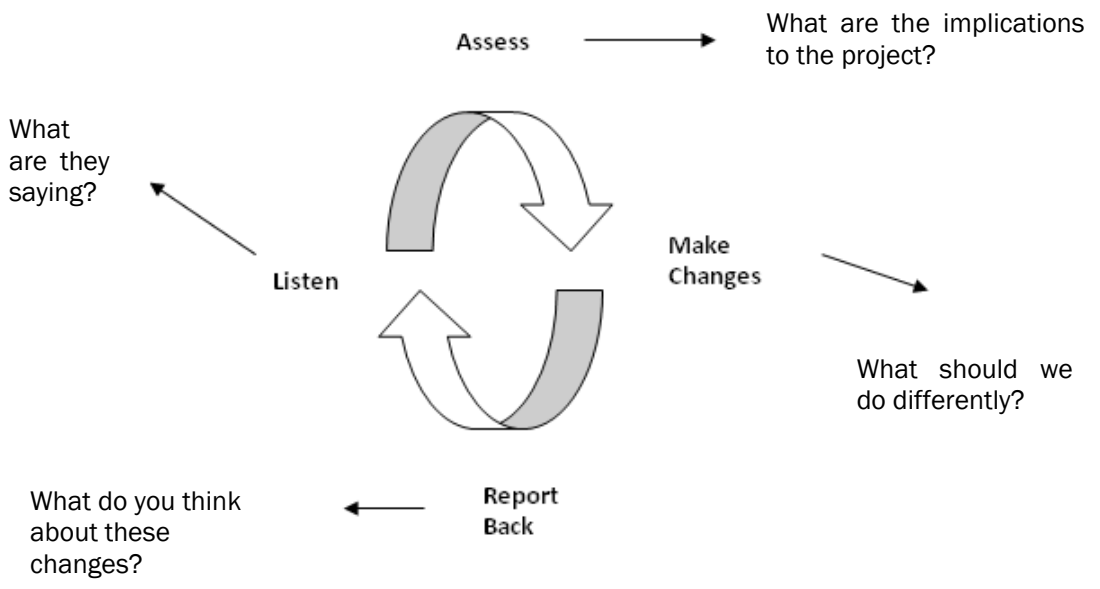

Figure 3: Input feedback protocol used at all times during the project. 


\subsubsection{Other information transfer tools}

Other tools used to transfer information about the conversion project included general media presence, factsheets, attendance at the South East Field Days, and an offer to industry bodies to be available to attend any industry field days or meetings by invitation.

\section{Final conversion model}

The final conversion model contained 4 different components (Figure 4), which were used to calculate the full volumetric allocation for each existing license. A detailed summary of the model is available in Carruthers et al. [10].

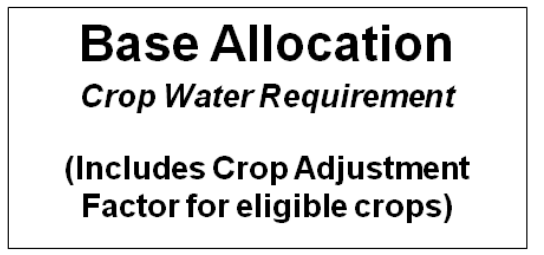

Delivery Component
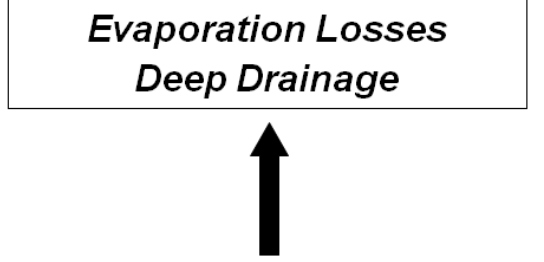

Available to all Licensees
Specialised Production Requirements

-Frost protection, Drift control, Crop cooling etc

\section{Bridging Volume}

Time to Adjust

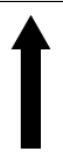

Available on Application

Figure 4: Volumetric conversion model.

Base Allocation was the core component of each license, and incorporated $\mathrm{ET}_{\mathrm{C}}$ as calculated using the methodology and crop coefficients $\left(\mathrm{K}_{\mathrm{C}}\right)$ from Allen et al. [3] fitted to the local growing season by consensus with local irrigators, and long term average climatic data sourced from the Bureau of Meteorology. Crop evapotranspiration $\left(\mathrm{ET}_{\mathrm{C}}\right)$ was combined with records of their existing areabased entitlement ("prior use") to calculate total Base Allocation for each HaIE license. Calculation of this component is discussed in detail in Skewes [4]. This was the only tradable component of the water licence.

The Delivery Component allowed for variable application efficiency between different system types, and was therefore available on all licenses. Initial delivery component figures were determined using well accepted application efficiency figures of $90 \%$ for drip, $85 \%$ for other pressurised systems, and $65 \%$ for surface irrigation systems (resulting in delivery components of an additional 
$11 \%, 18 \%$ and $54 \%$ of Base Allocation respectively). Subsequent field evaluations led to an increase in Delivery Component for surface irrigation in some zones, due to predominating soil conditions in those zones. Detailed discussion on calculation of Delivery Component is contained in Latcham et al. [6].

Specialised Production Requirements was water allowed for factors other than direct crop evapotranspiration or application losses. Frost control and crop cooling were included in this component, as was the irrigation for soil stabilisation in young vegetable crops. This component was available only on application, and required justification of the need for additional water. This component is further discussed in Pudney et al. [7].

Finally, because some irrigators were found to be operating well outside of the proposed total volume calculated for their license, a period of adjustment was provided, by virtue of the Bridging Volume. This was a short term allocation, designed to allow irrigators time to adjust their practices so that they could operate within their substantive volumetric allocation. Further discussion on Bridging Volume is contained in Latcham et al. [6].

The model was validated with the use of data from the FIST sites, as reported in Pudney [11].

\subsection{Resource limitations}

It may be noted that the model outlined above deals only with the conversion of existing area based licences to volumetric allocations. There is no reference in the model to matching the available water resource to the volume of water represented by volumetric allocations.

This is intentional, and is designed to clearly separate the volumetric conversion of existing licences (the process to establish equitable shares in the resource) from final allocation of the resource. In order for the conversion process to be transparent and equitable, the same methodology was applied across all licences within the region. This was done on the basis of crop water requirements, to ensure equity not only between different geographical locations, but between different crop types and irrigation systems.

At the end of the license conversion process, the second phase was to share the total water resource in a management zone (generally an administrative unit called a Hundred) amongst licenses in that management zone. Volumetric allocations are expressed as a share in the available resource, and the current Draft Water Allocation Plan [12] outlines adjustments to allocations in a range of management zones, in order to reduce overall allocation in those zones to match available water resources.

This principle of shares in the resource can be applied beyond the initial allocation of water. Because much of the water resource in the Limestone Coast is recharged locally, low rainfall over consecutive years can lead to reductions in water availability. If an appropriate annual assessment process were in place, allocations could be varied annually by a common percentage as required, to maintain the balance between available resource and allocated volume. However, such a provision is not included in the current Draft Water Allocation Plan [12]. 


\subsection{Water meters}

Although not discussed in detail here, the progressive roll-out of water meters in conjunction with the development of the volumetric conversion model was also an important aspect of the overall project. This will ultimately lead to improved management, both of the total water resource of the Limestone Coast, and of each irrigator's water allocation at the property and field scale.

\section{Conclusions}

The question asked in the title of this paper was "Is volumetric conversion a means to an end or an important process in its own right?" The conclusion reached is that, although the end of improved water resource management is of critical importance, the means by which that end was reached is of equal importance. To put it another way, the journey was as important as the destination, in part because the community shared the journey, and on the whole they arrived at the same destination.

The key conclusion of this paper is that the volumetric conversion model worked in the Limestone Coast region specifically because it was developed there and, more importantly, because of the process by which it was derived. The community was generally accepting of this model predominantly because they helped to develop it, and they had ownership of its components.

\section{References}

[1] Department for Environment, Heritage and Aboriginal Affairs. (1999). State Water Plan South Australia; Draft for Consultation Volume 1 (pp. 103). Adelaide: Department for Environment, Heritage and Aboriginal Affairs.

[2] South East Catchment Water Management Board. (2003). South East Catchment Water Management Plan 2003-2008 (pp. 204). Mount Gambier, South Australia.

[3] Allen, R. G., Pereira, L. S., Raes, D., and Smith, M. (1998). Crop Evapotranspiration; Guidelines for Computing Crop Water Requirements. Rome: Food and Agriculture Organization of the United Nations.

[4] Skewes, M. A. (2006). Definition of Net Irrigation Requirements in the South East of South Australia (pp. 57). Adelaide: Government of South Australia.

[5] Phocaides, A. (2001). Handbook on Pressurized Irrigation Techniques (pp. 195). Rome: Food and Agriculture Organization of the United Nations.

[6] Latcham, B., Pudney, S., and Carruthers, R. (2006). Volumetric Conversion in the South East of South Australia: Calculation of the Delivery Component and Bridging Volume Report DWLBC 2006/34.

[7] Pudney, S., Latcham, B., and Carruthers, R. (2006). Volumetric Conversion in the South East of South Australia: Calculation of Specialised Production Requirements Report DWLBC 2006/31. 
[8] Carruthers, R. (2006). Volumetric Conversion in the South East of South Australia: Community Consultation Processes Report DWLBC 2006/33.

[9] Carruthers, R., Latcham, B., and Pudney, S. (2006). Volumetric conversion in SE South Australia - changing perceptions mindsets and knowledge barriers before changing water licences. Paper presented at the Proceedings of the 2006 APEN International Conference, Beechworth, Victoria.

[10] Carruthers, R., Latcham, B., and Pudney, S. (2006). Volumetric Conversion in the South East of South Australia: Summary of the Conversion Model and Associated Conversion Rates Report DWLBC 2006/29.

[11] Pudney, S. (2006). Volumetric Conversion in the South East of South Australia: Validating the Allocation Model Report DWLBC 2006/30.

[12] South East Natural Resources Management Board. (2007). Water Allocation Plan for the Lower Limestone Coast Prescribed Wells Area Pre-draft for A2 consultation (pp. 90). Mount Gambier, South Australia. 